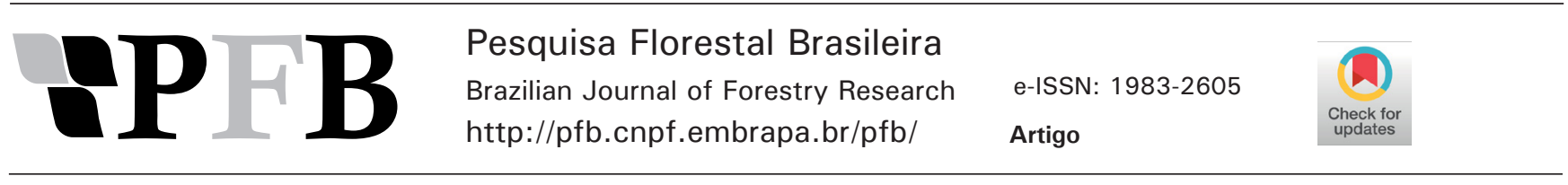

\title{
Análise da estrutura horizontal por densidade de Kernel como subsídio ao manejo florestal na Amazônia
}

\author{
Mariana Ferraz Oliveira ${ }^{+}(\mathbb{D})$, Patricia Povoa de Mattos $^{2}(\mathbb{D})$, Marilice Cordeiro Garrastazu2(i), Evaldo Muñoz Braz ${ }^{2(D)}$, \\ Afonso Figueiredo Filho' ${ }^{1}$ (D), Nelson Carlos Rosot ${ }^{1}$ (D) \\ ${ }^{1}$ Universidade Federal do Paraná, Avenida Prefeito Lothário Meissner, 632, Jardim Botânico, CEP 80210-170, Curitiba, PR, Brasil \\ ${ }^{2}$ Embrapa Florestas, Estrada da Ribeira, km 111, CEP 83411-000, Colombo, PR, Brasil
}

*Autor correspondente:
marianaferraz.floresta@gmail.com

Termos para indexação:

Floresta de Terra Firme

Dispersão

Sistema de Informação Geográfica

Index terms:

Terra Firme Forest

Dispersion

Geographic Information System

Histórico do artigo:

Recebido em 03/03/2020

Aprovado em 01/09/2020

Publicado em 26/02/2021

\section{(c) (i) $\Theta$}

Resumo - O presente trabalho teve como objetivo caracterizar a estrutura horizontal de uma área da Floresta Amazônica primária e a distribuição espacial das espécies Goupia glabra (Aubl.), Qualea spp. e Dipteryx odorata (Aubl.) Willd., por meio da análise da densidade de Kernel, visando embasar o planejamento do manejo florestal. A área de estudo localiza-se em Santa Carmem, microrregião de Sinop, estado do Mato Grosso (1.024 ha), onde foram mensurados todos os indivíduos com diâmetro a 1,30 m do solo $\geq 30 \mathrm{~cm}$. Foram calculadas as densidades, frequências e dominâncias, absolutas e relativas, além dos índices de valor de importância e de cobertura. A densidade de Kernel e a análise de dispersão em nível de espécie foram obtidas com o programa ArcGIS. A área foi classificada pelo índice de Shannon como de baixa diversidade e mais de $50 \%$ das espécies foram classificadas com tendência a agrupamento. Qualea spp. apresentou os maiores valores para todos os parâmetros analisados. Observou-se que a maior concentração de indivíduos se dá nas classes diamétricas passíveis de exploração. A aplicação da densidade de Kernel surge como uma ferramenta promissora ao planejamento do manejo florestal sustentável, permitindo a definição de zonas preferenciais para exploração sustentável.

\section{Horizontal structure analysis by Kernel density as basis to forest management in Amazonia}

\begin{abstract}
The present work aimed to characterize the horizontal structure of an area of primary Amazonian Forest and the spatial distribution of the species Goupia glabra (Aubl.), Qualea spp. and Dipteryx odorata (Aubl.) Willd. through the analysis of the Kernel density, aiming to support the planning of forest management. The study area is located in Santa Carmem, microregion of Sinop, state of Mato Grosso (1,024 ha), where all individuals with a diameter of $1,30 \mathrm{~m}$ from the ground $\geq 30 \mathrm{~cm}$ were measured. The absolute and relative densities, frequencies and dominances were calculated, in addition to the importance and coverage value indices. Kernel density and species level dispersion analysis were obtained using the ArcGIS program. The area was classified by the Shannon index as low diversity and more than $50 \%$ of the species were classified with a tendency to cluster. Qualea spp. presented the highest values for all analyzed parameters. It was observed that the highest concentration of individuals occurs in the diametric classes that can be exploited. The application of Kernel density appears as a promising tool for planning sustainable forest management, allowing the definition of preferential zones for sustainable exploitation.
\end{abstract}




\section{Introdução}

As florestas tropicais atraem interesse especial no que se refere aos estudos fitossociológicos, pois as lacunas de conhecimento existentes em termos geográficos impossibilitam o mapeamento da distribuição da biodiversidade, dificultando o planejamento para conservação e uso sustentável desses recursos (Hopkins, 2007). A maior parte da Amazônia brasileira é coberta por florestas de Terra Firme (cerca de 65\%), caracterizada por uma alta diversidade de espécies arbóreas, com grande variação florística (Oliveira et al., 2008). As diferentes condições ambientais e as distâncias entre as áreas geográficas em diferentes escalas desempenham um papel importante nas variações florísticas em toda a Amazônia (Carim et al., 2013), região ainda muito carente de informações úteis ao seu manejo e conservação (Andrade et al., 2015).

O inventário florestal é uma ferramenta básica a ser utilizada pelo gestor florestal, para detectar mudanças na floresta, oriundas de perturbações naturais ou humanas, como exploração e tratamentos silviculturais, sendo assim possível planejar a utilização da floresta sem lhe causar prejuízos (Silva \& Lopes, 1984; Péllico Netto \& Brena, 1997; Schneider \& Schneider, 2008; Dias Júnior et al., 2020). Adicionalmente, conta-se com ferramentas práticas que auxiliam o processamento dos dados provenientes do inventário florestal, o que proporciona maior agilidade para a realização de análises de vegetação. Segundo Freitas et al. (2005), o uso de sistemas de informação como base para a tomada de decisão na conservação e exploração sustentável dos recursos florestais se apresenta como fonte de conhecimento para profissionais da área florestal.

Na Amazônia, o uso de SIG já é consolidado em várias vertentes, como: combate ao desmatamento ilegal (Domingues \& Bermann, 2012); estimativa de biomassa (Martins et al., 2011; Figueiredo et al., 2016); análise morfométrica e socioambiental (Umetsu et al., 2012; Vale \& Bordalo, 2020); identificação de vestígios arqueológicos (Cunha \& Bias, 2019); identificação de espécies nativas (Moras Filho et al., 2017); análise da transformação da floresta e uso e ocupação do solo (Silva \& França, 2013; Arenas et al., 2015; Caña et al., 2015); infraestrutura de transportes (Costa et al., 2001); alocação de pátios de armazenamento (Silva et al., 2018, 2020); subsidio para inventários e manejo florestal (Broza et al., 2012; Klauberg et al., 2013).
Uma das formas para o melhor conhecimento e entendimento das espécies florestais é a análise fitossociológica (Barros, 1986; Ubialli et al., 2009; Costa et al., 2018), a qual possibilita o estabelecimento de estratégias para conservação e manejo da floresta, pois práticas de exploração desordenada dos recursos florestais podem causar impactos negativos (Hopkins, 2007; Condé \& Tonini, 2013; Batista et al., 2015).

Neste contexto, a análise da densidade de Kernel surge como promissora ferramenta de auxílio na análise da distribuição espacial das espécies ou grupos de espécies de interesse, permitindo um planejamento direcionado, principalmente no que se refere à alocação das redes viárias e pátios de estocagem. Trabalhos que usam a densidade de Kernel são observados para a região Amazônica, mas basicamente como indicador de áreas de desmatamento e focos de calor (Ferreira \& Sano, 2013; Souza et al., 2013; Andrade Filho et al., 2017; Araújo \& Figueiredo, 2017; Tavares et al., 2019). Existem inúmeros planos de manejo na região Amazônica, fiscalizados por órgãos executores de política estadual ambiental. Estes órgãos avaliam não só a quantidade da madeira explorada como a veracidade sobre as espécies que estão sendo extraídas. Mas, apesar da disponibilidade de dados que fornecem informações sobre a floresta Amazônica, esses raramente são utilizados na busca de sua compreensão.

Assim, apesar de auxiliares no planejamento da extração, os planos de manejo não são utilizados para entendimento mais aprofundado sobre a estrutura da população das espécies de interesse. Estes poderiam fornecer importantes informações ou dar suporte para análises sobre a distribuição geográfica das espécies, sua abundância ou limitações de habitat. O presente trabalho teve como objetivo caracterizar a estrutura horizontal de uma área de Floresta Amazônica primária e a distribuição espacial das espécies Goupia glabra (Aubl.), Qualea spp. e Dipteryx odorata (Aubl.) Willd., por meio da análise da densidade de Kernel, visando embasar o planejamento do manejo florestal.

\section{Material e métodos}

A área de estudo está localizada no município de Santa Carmem, inserida na microrregião de Sinop, região norte do estado do Mato Grosso. É uma região de Floresta Ombrófila Densa de Terra Firme primária, contando com a presença de espécies de grande importância comercial 
como Qualea spp., Goupia glabra, Mezilaurus itauba, Apuleia leiocarpa, Dipteryx odorata, entre outras, além de espécies de importância ecológica como Bertholletia excelsa (Passos \& Mason, 2005).

Consiste em uma área de 1.024 ha, com plano de manejo florestal aprovado pelos órgãos competentes. No censo florestal realizado pré-exploração, foram medidos os diâmetros das árvores a $1,30 \mathrm{~m}$ do solo (DAP) $\geq 30$ $\mathrm{cm}$, sendo identificadas e codificadas todas as espécies. O sistema de referência Datum Sirgas 2000 foi usado para a coleta de dados, sendo georreferenciados com GPS Garmim a cada 400 metros, com aferição e correção geodésica no início e no final do projeto. A área líquida para o manejo florestal, após descontar as áreas de preservação permanentes (APPs), é 939,54 ha.

A seleção de espécies florestais para análise individual neste estudo foi conduzida com base na demanda por informações que auxiliem no manejo sustentável das principais espécies de valor econômico madeirável na região.

Com o auxílio do software ArcGIS, foram geradas parcelas simuladas de 1 ha, distribuídas na forma de um reticulado cobrindo toda a área de estudo. As parcelas com área inferior a $1 \mathrm{ha}$, presentes nas áreas limítrofes da unidade de manejo ou de áreas de parcelas permanentes, não foram consideradas para essa análise, totalizando, portanto, 789 parcelas inteiras compreendidas na área de estudo.

Foi gerada uma matriz de atributos, contendo informações em nível de parcela, para processamento no software Mata Nativa 2.0, tendo como dados de entrada: número de identificação da árvore; DAP $(\mathrm{cm})$; código e nome da espécie. Foram determinadas a densidade, frequência e dominância, absolutas e relativas, bem como o índice de valor de importância, valor de cobertura, índice de Shannon (H') e índice de agregação de McGuinnes (IGA), para o total de espécies observadas na área. De forma a complementar as análises da distribuição espacial e de dispersão individual das espécies selecionadas, foi utilizado o software ArcGIS (SIG).

Para o cálculo da dispersão em nível de espécie, foi adotado o método do vizinho mais próximo, que consiste na mensuração e estimativa da distância usada para verificar se a espécie apresenta padrão agregado, aleatório ou uniforme, chamada de z-score (desvio padrão). O valor do padrão espacial dos dados (p-valor) define a área central do gráfico, partindo do pressuposto que os dados são distribuídos aleatoriamente. Se o valor do z-score for deslocado à esquerda da curva normal, o padrão é definido como agregado e, quanto mais à direita da curva, mais dispersa é a distribuição das árvores daquela espécie (ou uniforme). Quando o valor do z-score é igual à zero, ocupando a posição central do gráfico, diz-se que a espécie apresenta padrão aleatório de distribuição (Esri, 2009).

A análise de densidade de Kernel foi representada graficamente em função do número de indivíduos, com base em suas coordenadas geográficas. Essa análise considera uma vizinhança circular ao redor de cada ponto de amostra, correspondente ao raio de influência, sendo aplicada uma função matemática de valor 1 , na posição do ponto, a 0 na fronteira da vizinhança. $\mathrm{O}$ valor para a célula é a soma dos valores Kernel sobrepostos e divididos pela área do raio de influência (Silverman, 1986).

O raio usado para a análise, no entanto, é um campo de preenchimento opcional. Sendo assim, foram testados valores gerados automaticamente (quando o campo é deixado em branco) e usando a equação 1 para o cálculo da distância média entre árvores, em função do número de árvores e do tamanho da área, segundo Braz et al. (2015).

Equação 1.

$$
d=\sqrt{\frac{A}{N}}
$$

Em que: $\mathrm{d}=$ distância média entre árvores $(\mathrm{m}) ; \mathrm{A}=$ área $\left(\mathrm{m}^{2}\right) ; \mathrm{N}=$ número de árvores.

Foram também obtidos mapas da densidade de Kernel dos indivíduos divididos em três classes de diâmetro: a) remanescente $(30,0 \mathrm{~cm}$ a $49,9 \mathrm{~cm}), \mathrm{b})$ comercial $(50,0 \mathrm{~cm}$ a 79,9 cm) e c) senescente (acima de 80,0 cm). As classes de DAP para a análise foram arbitradas, considerando que as florestas destinadas aos planos de manejo são obrigatoriamente levantadas mediante censo, ou seja, inventário $100 \%$ acima da classe de DAP de $30 \mathrm{~cm}$, permitindo o corte apenas daquelas árvores acima de classe de $50 \mathrm{~cm}$ (Brasil, 2006). As árvores com DAP acima da classe de $80 \mathrm{~cm}$ foram consideradas como potencialmente em fase inicial de estagnação ou início de senescência, baseando-se no trabalho de Braz et al. (2012). Em ambas as situações, consideraram-se cinco classes de densidade de Kernel: muito baixa, baixa, média, alta e muito alta, variando da cor azul para a vermelha, respectivamente. 


\section{Resultados}

No levantamento florístico foram observadas 22 famílias, 34 gêneros e 36 espécies florestais, tendo destaque a família Fabaceae, seguida por Vochysiaceae, Sapotaceae, Lauraceae, Caesalpinaceae e Anacardiaceae (Tabela 1). As demais famílias apresentaram apenas uma espécie cada.

As espécies que se destacaram por ocorrerem em um número relevante de unidades amostrais foram Qualea spp., ocorrendo em $99 \%$ das unidades amostrais de um total de 789, seguida por Erisma uncinatum (94\%), Trattinnickia sp. (93\%), Goupia glabra (88\%), Mezilaurus itauba (75\%) e Dipteryx odorata (71\%). Cabe destaque também para as espécies Sclerolobium sp., Chorisias speciosa, Cordia goeldiana, Lafoensia pacari e Neoxythece robusta, que aparecem em somente uma das unidades amostrais.

Qualea spp. apresentou as maiores estimativas de densidade, frequência e dominância relativas, valor de cobertura e valor de importância, sendo consideravelmente superiores às demais espécies. Quando se compara com a espécie que ocupou a segunda colocação nos parâmetros analisados (Erisma uncinatum), o cambará (Qualea spp.) apresentou densidade relativa $(33,9 \%)$, pelo menos três vezes maior.

Qualea spp. apresentou também maior valor de importância, seguida por Erisma uncinatum, Trattinnickia busseraefolia, Goupia glabra, Mezilaurus itauba e Dipteryx odorata. Dentre as 36 espécies observadas na área de estudo, 18 apresentaram valor de importância inferior a 1\%, dentre elas Copaifera martii (copaíba), Aspidosperma polyneuron (peroba) e Hymenaea courbaril (jatobá), consideradas espécies de madeira nobre. Apesar da família Fabaceae apresentar o maior número de espécies, a família Vochysiaceae apresentou o maior valor de importância, pelo maior número de indivíduos registrados.

Na Figura 1 estão representadas as densidades obtidas com a realização do censo na referida área e, também, as densidades obtidas individualmente para Qualea spp. (cambará), Goupia glabra (cupiúba) e Dipteryx odorata (cumaru), divididas em cinco classes (densidade de Kernel), variando de valores menos densos (azul) para valores de maior densidade de indivíduos (vermelho). Os raios calculados para o censo e para as espécies variaram de $35 \mathrm{~m}$ a $370 \mathrm{~m}$.
Com o mapa do censo (Figura 1a), observa-se que a área apresenta uma densidade alta ou muito alta de árvores, demonstrando valores baixos de densidade somente na região limítrofe. Qualea spp. (Figura 1b) apresentou pontos de maiores densidades espalhados pela área, mas diferente do que foi observado para Dipteryx odorata e Goupia glabra (Figuras 1c e 1d), que apresentaram densidades variando de muito alta em regiões mais centralizadas a muito baixa em regiões limítrofes. Os pontos com densidades muito alta para o cambará foram seguidos por pontos de baixas densidades, mostrando que a espécie ocorre em reboleiras.

O índice de Shannon (H') observado para o total das 36 espécies, com inclusão a partir de $30 \mathrm{~cm}$ de diâmetro, foi 2,45 indicando que a área de estudo apresenta baixa diversidade.

De acordo com a classificação de McGuinnes (IGA), seis espécies foram classificadas como de ocorrência uniforme (IGA < 1,0), sendo: duas espécies de angelim (Hymenolobium petraeum e Parkia pendula), duas de sucupira (Pterodon pubescens e Bowdichia nitida), cumaru (Dipteryx odorata) e jatobá (Hymenaea courbaril). Nove espécies foram classificadas com ocorrência aleatória $(\mathrm{IGA}=1,0)$, cabendo destaque para tamboril (Enterolobium maximum) que apresentou elevado número de árvores na área, quando comparado com as demais espécies que apresentaram número de indivíduos pouco expressivos. Aproximadamente 53\% das espécies observadas no local de estudo apresentaram tendência ao agrupamento $(1,0<\mathrm{IGA}<2,0)$, dentre elas, espécies com importância econômica para os produtos madeiráveis, como cedrinho (Erisma uncinatum), amescla (Trattinnickia busseraefolia), cupiúba (Goupia glabra), itaúba (Mezilaurus itauba), garapeira (Apuleia leiocarpa), caroba (Jacaranda copaia) e peroba (Aspidosperma polyneuron). As espécies cambará (Qualea spp.) e castanheira (Bertholletia excelsa) foram classificadas como agregadas (IGA $>2,0)$.

A dispersão de Qualea spp., Goupia glabra e Dipteryx odorata, considerando o algorítimo do vizinho mais próximo, está representada na Figura 2. Qualea spp. apresentou comportamento gregário (z-score $=-6,71$ e p-valor $=0,00)$ e as espécies Goupia glabra (z-score $=2,27$ e p-valor $=0,02)$ e Dipteryx odorata $(\mathrm{z}$-score $=$ $3,15$ e p-valor $=0,01)$ tiveram padrão de comportamento disperso. 
Tabela 1. Resultados florísticos (árvores com DAP $\geq 30 \mathrm{~cm}$ ) para a área de manejo florestal (789 ha) avaliada no município de Santa Carmem, MT.

Table 1. Floristic results (trees with $\mathrm{DBH} \geq 30 \mathrm{~cm}$ ) for the forest management area (789 ha) evaluated in the municipality of Santa Carmem, MT.

\begin{tabular}{|c|c|c|c|c|c|c|c|c|c|c|c|c|}
\hline Espécie & Família & $\mathbf{N}$ & $\mathbf{U a}$ & $\mathbf{A B}$ & DR & FR & DoR & $\mathrm{VC}$ & VI & DAPmín & DAPméd & DAPmáx \\
\hline Qualea spp. & Vochysiaceae & 7.844 & 781 & $1.876,8$ & 33,9 & 9,1 & 27,5 & 30,7 & 23,5 & 32,1 & 54,0 & 114,9 \\
\hline Erisma uncinatum Warm & Vochysiaceae & 2.287 & 742 & $1.051,1$ & 9,9 & 8,7 & 15,4 & 12,6 & 11,3 & 32,1 & 73,7 & 142,9 \\
\hline $\begin{array}{l}\text { Trattinnickia buseraefolia (Mart.) } \\
\text { Willd }\end{array}$ & Burseraceae & 2.305 & 736 & 814,1 & 9,9 & 8,6 & 11,9 & 10,9 & 10,8 & 32,1 & 64,0 & 161,4 \\
\hline Goupia glabra Aubl. & Goupiaceae & 1.926 & 693 & 746,2 & 8,3 & 8,1 & 10,9 & 9,6 & 9,1 & 32,1 & 67,0 & 174,7 \\
\hline $\begin{array}{l}\text { Mezilaurus itauba (Meisn.) Taub. } \\
\text { ex Mez. }\end{array}$ & Lauraceae & 1.241 & 593 & 379,3 & 5,4 & 6,9 & 5,6 & 5,5 & 5,9 & 32,1 & 60,2 & 132,7 \\
\hline Dipteryx odorata (Aubl.) Willd & Fabaceae & 921 & 562 & 247,3 & 4,0 & 6,6 & 3,6 & 3,8 & 4,7 & 32,1 & 56,4 & 121,3 \\
\hline $\begin{array}{l}\text { Cnidoscolus phyllacanthus Mull } \\
\text { Arg. }\end{array}$ & Euphorbiaceae & 835 & 511 & 178,7 & 3,6 & 6,0 & 2,6 & 3,1 & 4,1 & 31,5 & 51,0 & 99,3 \\
\hline Micropholis spp. & Sapotaceae & 809 & 489 & 160,1 & 3,5 & 5,7 & 2,3 & 2,9 & 3,8 & 32,8 & 49,5 & 93,6 \\
\hline Ocotea spp. & Lauraceae & 794 & 490 & 163,0 & 3,4 & 5,7 & 2,4 & 2,9 & 3,8 & 32,1 & 50,2 & 107,9 \\
\hline Jacaranda copaia (Aubl.) D. Don & Bignoniaceae & 562 & 384 & 121,3 & 2,4 & 4,5 & 1,8 & 2,1 & 2,9 & 32,1 & 51,5 & 90,7 \\
\hline Qualea paraenses Ducke & Vochysiaceae & 521 & 361 & 93,8 & 2,2 & 4,2 & 1,4 & 1,8 & 2,6 & 30,6 & 47,0 & 87,5 \\
\hline $\begin{array}{l}\text { Apuleia leiocarpa (Vogel) } \\
\text { J.F.Macbr }\end{array}$ & Fabaceae & 500 & 316 & 181,4 & 2,2 & 3,7 & 2,7 & 2,4 & 2,8 & 32,5 & 65,4 & 127,0 \\
\hline Bertholletia excelsa Bonpl & Lecythidaceae & 590 & 109 & 246,0 & 2,5 & 1,3 & 3,6 & 3,1 & 2,5 & 38,5 & 70,1 & 138,1 \\
\hline Astronium spp. & Anacardiaceae & 335 & 265 & 63,7 & 1,4 & 3,1 & 0,9 & 1,2 & 1,8 & 32,8 & 48,1 & 102,8 \\
\hline Hymenolobium petraeum Ducke & Fabaceae & 271 & 238 & 85,7 & 1,2 & 2,8 & 1,3 & 1,2 & 1,7 & 33,1 & 60,4 & 141,6 \\
\hline $\begin{array}{l}\text { Parkia pendula (Willd.) Benth. } \\
\text { ex Walp }\end{array}$ & Fabaceae & 238 & 214 & 85,5 & 1,0 & 2,5 & 1,2 & 1,1 & 1,6 & 32,5 & 65,0 & 142,9 \\
\hline Enterolobium maximum Ducke & Fabaceae & 207 & 182 & 65,9 & 0,9 & 2,1 & 1,0 & 0,9 & 1,3 & 35,3 & 62,2 & 102,5 \\
\hline Bowdichia virgilioides Kunth & Fabaceae & 201 & 172 & 63,8 & 0,9 & 2,0 & 0,9 & 0,9 & 1,3 & 33,1 & 61,1 & 124,5 \\
\hline Diplotropis purpurea (Rich.) & Fabaceae & 195 & 171 & 27,8 & 0,8 & 2,0 & 0,4 & 0,6 & 1,1 & 31,2 & 42,1 & 63,0 \\
\hline $\begin{array}{l}\text { Schefflera morototoni (Aubl.) } \\
\text { Maguire }\end{array}$ & Araliaceae & 129 & 116 & 24,7 & 0,6 & 1,4 & 0,4 & 0,5 & 0,8 & 33,7 & 48,6 & 74,2 \\
\hline $\begin{array}{l}\text { Caryocar villosum var. } \\
\text { macrophyllum Wittm }\end{array}$ & Caryocaraceae & 99 & 90 & 41,1 & 0,4 & 1,1 & 0,6 & 0,5 & 0,7 & 35,3 & 69,4 & 149,3 \\
\hline Copaifera martii Hayne & Fabaceae & 103 & 96 & 31,9 & 0,4 & 1,1 & 0,5 & 0,5 & 0,7 & 33,7 & 61,2 & 96,1 \\
\hline $\begin{array}{l}\text { Aspidosperma polyneuron Müll. } \\
\text { Arg }\end{array}$ & Apocynaceae & 62 & 54 & 22,9 & 0,3 & 0,6 & 0,3 & 0,3 & 0,4 & 33,1 & 66,5 & 121,6 \\
\hline Hymenaea courbaril L. & Fabaceae & 44 & 44 & 17,9 & 0,2 & 0,5 & 0,3 & 0,2 & 0,3 & 37,2 & 70,0 & 106,6 \\
\hline Pterodon pubescens Benth & Fabaceae & 41 & 41 & 8,9 & 0,2 & 0,5 & 0,1 & 0,1 & 0,3 & 33,4 & 51,3 & 80,8 \\
\hline Simarouba amara Aubl & Simarubaceae & 41 & 36 & 6,7 & 0,2 & 0,4 & 0,1 & 0,1 & 0,2 & 32,5 & 44,7 & 75,8 \\
\hline Spondias lutea Linn & Anacardiaceae & 31 & 30 & 7,6 & 0,1 & 0,3 & 0,1 & 0,1 & 0,2 & 37,6 & 54,3 & 98,4 \\
\hline Bowdichia nitida Spruce ex Benth & Fabaceae & 12 & 12 & 4,6 & 0,1 & 0,1 & 0,1 & 0,1 & 0,1 & 56,0 & 69,2 & 82,4 \\
\hline Sclerolobium spp. & Caesalpinaceae & 3 & 3 & 1,0 & 0,0 & 0,0 & 0,0 & 0,0 & 0,0 & 60,2 & 66,3 & 71,0 \\
\hline Apeiba burchelli Sprague & Tiliaceae & 3 & 3 & 0,8 & 0,0 & 0,0 & 0,0 & 0,0 & 0,0 & 52,8 & 57,6 & 66,5 \\
\hline $\begin{array}{l}\text { Erythroxylum argentinum } \mathrm{O} \text {. E. } \\
\text { Schulz }\end{array}$ & Erythroxylaceae & 2 & 2 & 0,4 & 0,0 & 0,0 & 0,0 & 0,0 & 0,0 & 50,3 & 50,4 & 50,6 \\
\hline Desconhecida & & 2 & 2 & 0,4 & 0,0 & 0,0 & 0,0 & 0,0 & 0,0 & 51,2 & 52,4 & 53,5 \\
\hline Sclerolobium spp. & Fabaceae & 1 & 1 & 0,3 & 0,0 & 0,0 & 0,0 & 0,0 & 0,0 & 61,1 & 61,1 & 61,1 \\
\hline Chorisia speciosa A. St.-Hil & Bombacaceae & 1 & 1 & 0,3 & 0,0 & 0,0 & 0,0 & 0,0 & 0,0 & 58,6 & 58,6 & 58,6 \\
\hline Cordia goeldiana Huber & Boraginaceae & 1 & 1 & 0,3 & 0,0 & 0,0 & 0,0 & 0,0 & 0,0 & 58,2 & 58,2 & 58,2 \\
\hline Lafoensia pacari A.St. -Hil & Lythraceae & 1 & 1 & 0,2 & 0,0 & 0,0 & 0,0 & 0,0 & 0,0 & 54,7 & 54,7 & 54,7 \\
\hline $\begin{array}{l}\text { Neoxythece robusta (M. \& Eichl.) } \\
\text { Aubr. \& Pell }\end{array}$ & Sapotaceae & 1 & 1 & 0,2 & 0,0 & 0,0 & 0,0 & 0,0 & 0,0 & 53,8 & 53,8 & 53,8 \\
\hline Total & & 23.159 & 789 & $6.821,9$ & 100 & 100 & 100 & 100 & 100 & 30,6 & 58,8 & 174,7 \\
\hline
\end{tabular}

*N = número de árvores; $\mathrm{Ua}=$ unidades amostrais; $\mathrm{AB}=$ área basal $\left(\mathrm{m}^{2}\right)$; $\mathrm{DR}=$ densidade relativa $(\%)$; $\mathrm{FR}=$ frequência relativa $(\%)$; DoR = dominância relativa (\%); $\mathrm{VC}=$ valor de cobertura (\%); VI = valor de importância (\%); DAP = diâmetro a 1,30 m do solo (cm); mín., méd., máx., = mínimo, médio e máximo, respectivamente. 
a

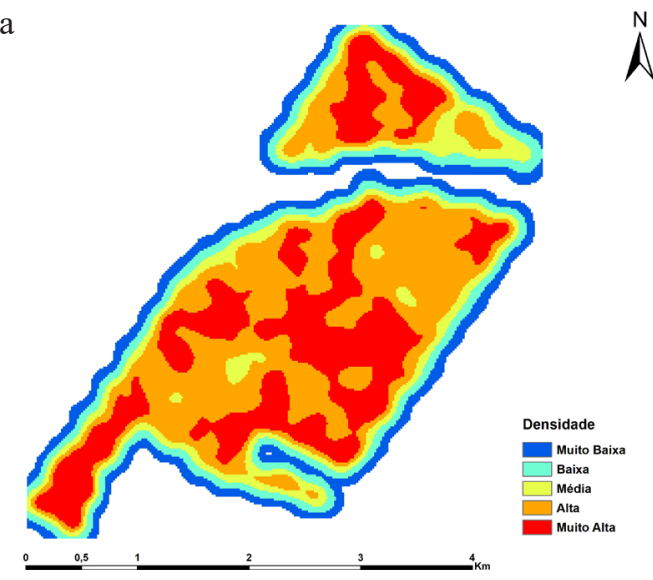

c

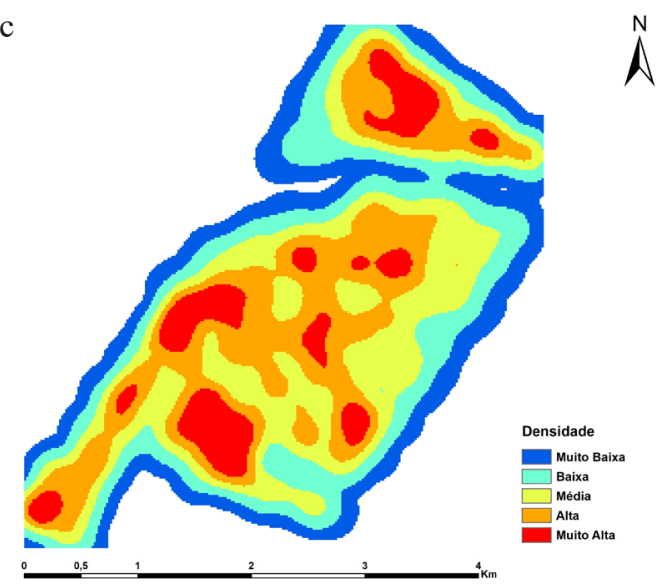

b

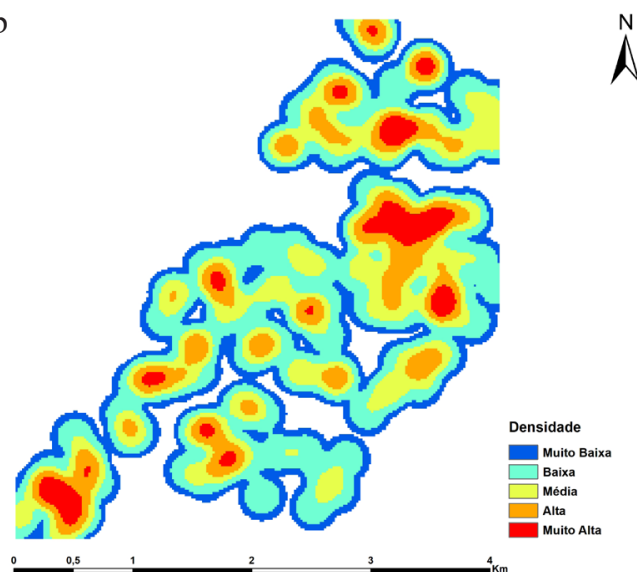

d

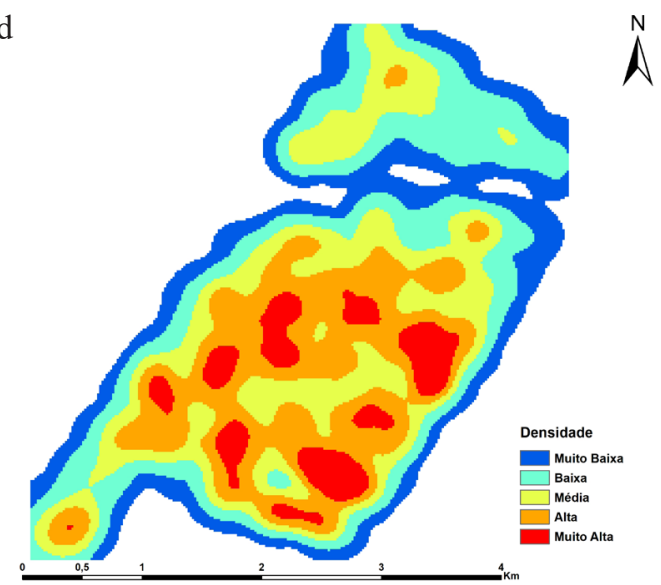

Figura 1. Densidades de Kernel para: a) censo, b) Qualea spp., c) Dipteryx odorata e d) Goupia glabra na área de manejo florestal avaliada no município de Santa Carmem, MT.

Figure 1. Kernel densities for: a) census, b) Qualea spp., C) Dipteryx odorata and d) Goupia glabra in the forest management area evaluated in the municipality of Santa Carmem, MT. 
a

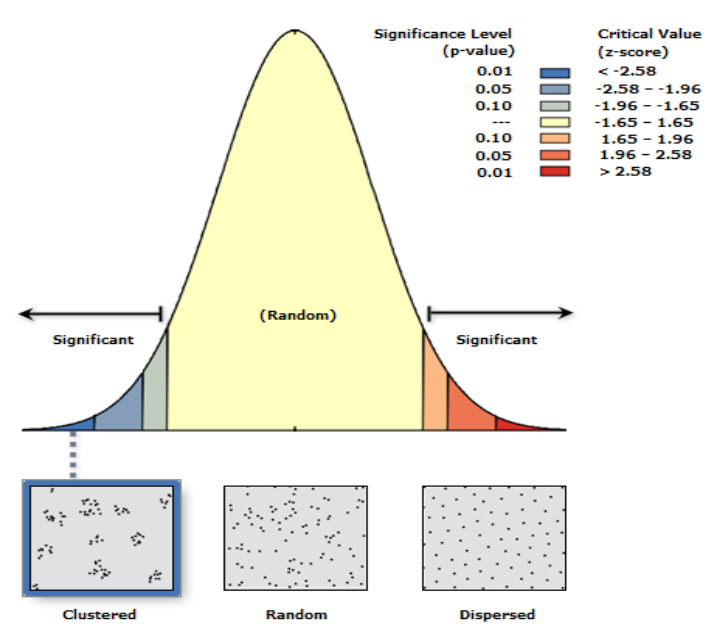

b

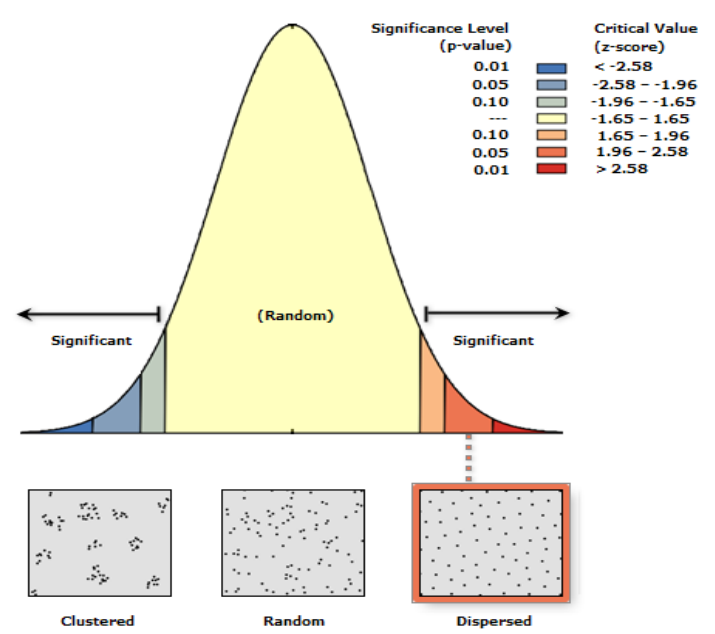

c

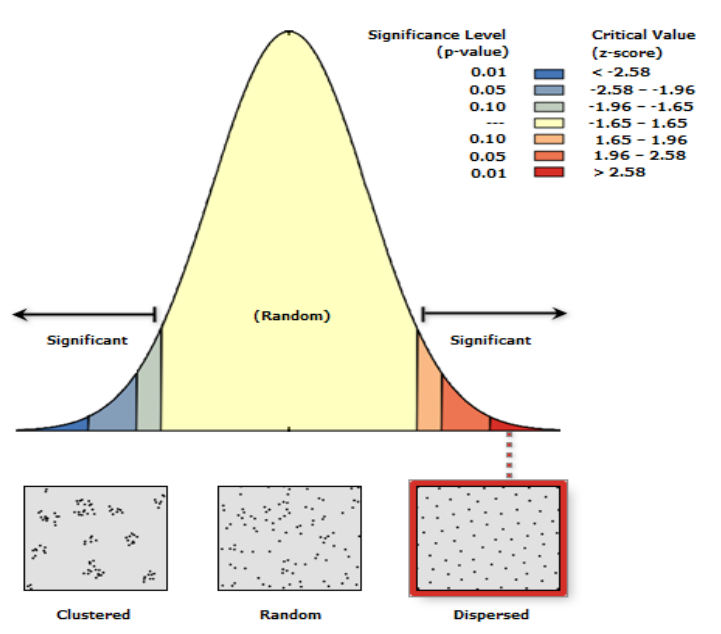

Figura 2. Dispersão dos indivíduos das espécies a) Qualea spp., b) Goupia glabra e c) Dipteryx odorata, contemplados no censo, na área de manejo florestal, no município de Santa Carmem, MT.

Figure 2. Dispersion of individuals of the species a) Qualea spp., b) Goupia glabra and c) Dipteryx odorata, included in the census, in the forest management area, in the municipality of Santa Carmen, MT.

*Desvio padrão da média das distâncias $= \pm 2,58(\mathrm{p} \pm 0,01)$.

A distribuição diamétrica dos indivíduos contemplados no censo está apresentada na Tabela 2. Observa-se que a maior concentração de indivíduos está no centro de classe de diâmetro $(\mathrm{DAP})=45 \mathrm{~cm}$, com densidade absoluta de 7,23 e dominância absoluta de 1,7. As maiores classes em número de indivíduos na sequência são: centros de classes de DAP $=55$ e $65 \mathrm{~cm}$, com densidade absoluta de 7,04 e 4,6 e dominância absoluta de 1,14 e 1,5, respectivamente. A distribuição " $J$ " invertido ocorre a partir da classe de $45 \mathrm{~cm}$. Observa-se também que, a partir da classe de DAP $=65 \mathrm{~cm}$, o número de árvores diminui de forma crescente (redução de $30 \%$ a $65 \%$ em relação à classe anterior). 
Tabela 2. Distribuição diamétrica dos indivíduos contemplados no censo, na área de manejo florestal avaliada no município de Santa Carmem, MT.

Table 2. Diametric distribution of individuals included in the census in the forest management area assessed in the municipality of Santa Carmem, MT.

\begin{tabular}{ccccc}
\hline $\begin{array}{c}\text { Centro de classes } \\
\text { de DAP }(\mathbf{c m})\end{array}$ & $\mathbf{N}$ & $\mathbf{A B}$ & $\mathbf{D A}$ & $\mathbf{D o A}$ \\
\hline 35 & 2.333 & 254,36 & 2,33 & 0,25 \\
45 & 7.042 & $1.138,23$ & 7,04 & 1,14 \\
55 & 7.232 & $1.701,56$ & 7,23 & 1,70 \\
65 & 4.592 & $1.504,33$ & 4,59 & 1,50 \\
75 & 2.516 & $1.105,51$ & 2,52 & 1,11 \\
85 & 1.433 & 805,52 & 1,43 & 0,81 \\
95 & 833 & 584,64 & 0,83 & 0,59 \\
105 & 474 & 406,58 & 0,47 & 0,41 \\
115 & 216 & 222,36 & 0,22 & 0,22 \\
125 & 114 & 137,80 & 0,11 & 0,14 \\
135 & 42 & 59,25 & 0,04 & 0,06 \\
145 & 15 & 24,92 & 0,02 & 0,03 \\
155 & 5 & 9,20 & 0,01 & 0,01 \\
165 & 2 & 4,11 & 0,00 & 0,00 \\
175 & 1 & 2,40 & 0,00 & 0,00 \\
\hline Total & $\mathbf{2 6 . 8 5 0}$ & $\mathbf{7 . 9 6 0 , 8}$ & $\mathbf{2 6 , 8 5}$ & $\mathbf{7 , 9 6}$ \\
\hline
\end{tabular}

$* \mathrm{~N}=$ number of trees; $\mathrm{AB}=$ basal area $\left(\mathrm{m}^{2} / \mathrm{ha}\right) ; \mathrm{DA}=$ absolute density; DoA $=$ absolute dominance.

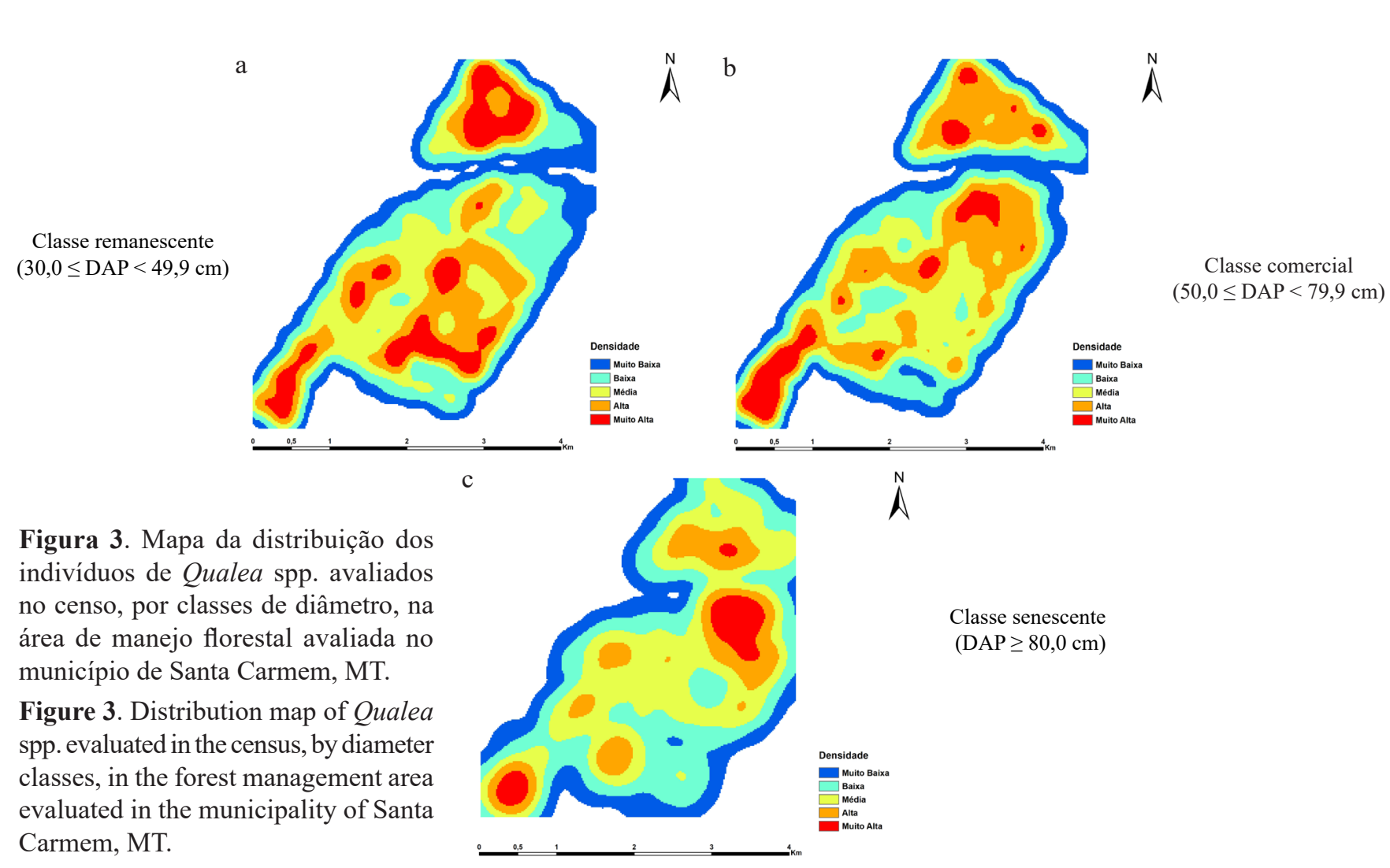

A distribuição dos indivíduos de Qualea spp., Goupia glabra e Dipteryx odorata em três classes de diâmetro estão representadas nas Figuras 3, 4 e 5, respectivamente, sendo que a primeira classe com árvores apresentando $30,0 \mathrm{~cm} \leq$ DAP $<49,9 \mathrm{~cm}$, a segunda $50,0 \mathrm{~cm} \leq$ DAP $<$ $79,9 \mathrm{~cm}$ e a terceira classe DAP $\geq 80,0 \mathrm{~cm}$. Qualea spp. apresentou grande estoque de árvores nas duas classes menores (3.687 árvores com 30,0 $\leq \mathrm{DAP}<49,9 \mathrm{~cm} \mathrm{e}$ 5.274 árvores com 50,0 $\leq \mathrm{DAP}<79,9 \mathrm{~cm}$ ). Porém, o número de indivíduos com $\mathrm{DAP} \geq 80,0 \mathrm{~cm}$ não chega a 2,3\% da população (Figura 3 ).

Goupia glabra apresentou maior número de árvores na classe comercial (1.090 árvores com 50,0 $\leq$ DAP $<79,9 \mathrm{~cm}$ ), sendo observadas 530 árvores com 30,0 $\leq \mathrm{DAP}<49,9 \mathrm{~cm}$ e 583 árvores com DAP $\geq 80,0 \mathrm{~cm}$.

D. odorata (Figura 5) apresentou a menor densidade na área de estudo, com maior representatividade nas duas primeiras classes (414 árvores com 30,0 $\leq$ DAP $<49,9 \mathrm{~cm}$ e 582 árvores com 50,0 $\leq$ DAP $<79,9 \mathrm{~cm}$ ) com pequena superioridade de indivíduos na classe passível de exploração. Na classe de DAP $\geq 80,0 \mathrm{~cm}$ foi observada diminuição do número de árvores (apenas $8,1 \%$ do total). 
a

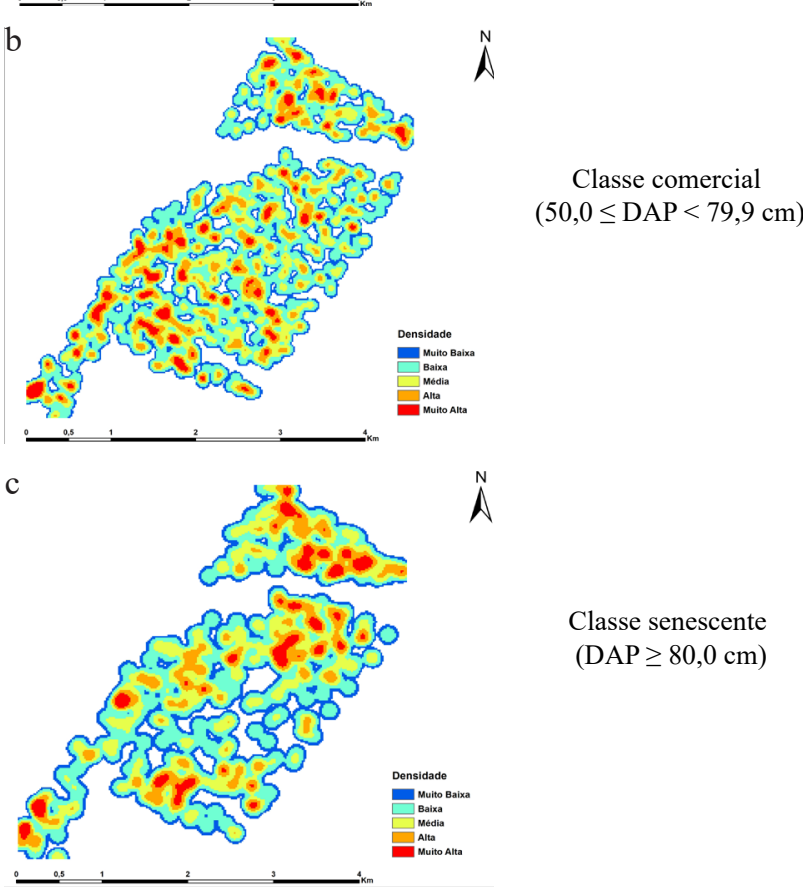

Figura 4. Mapa da distribuição dos indivíduos de Goupia glabra, por classes de diâmetro, na área de manejo florestal avaliada, no município de Santa Carmem, MT.

Figure 4. Map of the distribution of individuals of Goupia glabra, by diameter classes, in the forest management area evaluated, in the municipality of Santa Carmem, MT.

\section{Discussão}

Alguns trabalhos de levantamentos florísticos, com limite de inclusão de árvores com DAP $\geq 10 \mathrm{~cm}$ (Condé \& Tonini, 2013; Reis et al., 2014; Silva et al., 2015; Costa et al., 2018), mesmo em áreas de apenas alguns hectares, mostram maiores valores para famílias, gêneros e espécies quando comparados aos observados nesse trabalho (Tabela 1). Essa diferença se justifica pela não inclusão de indivíduos do sub-bosque ou que não atingem grandes dimensões de DAP, pois, nesta a

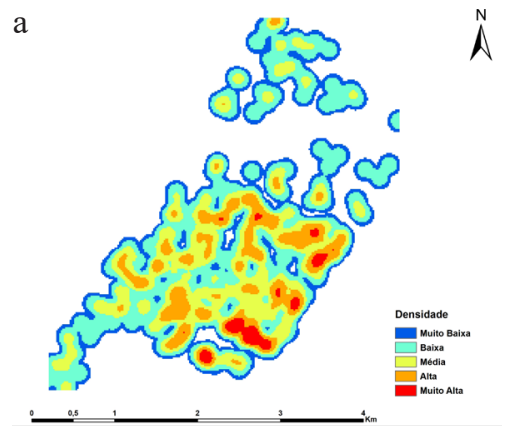

b

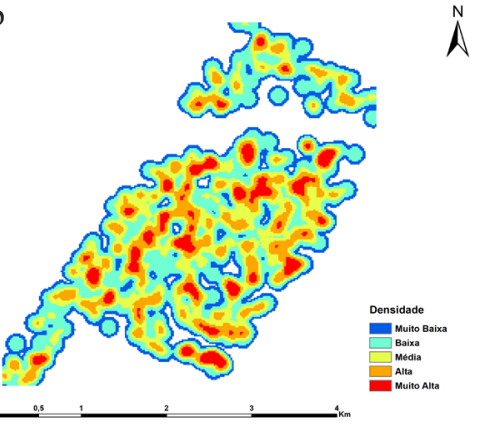

c

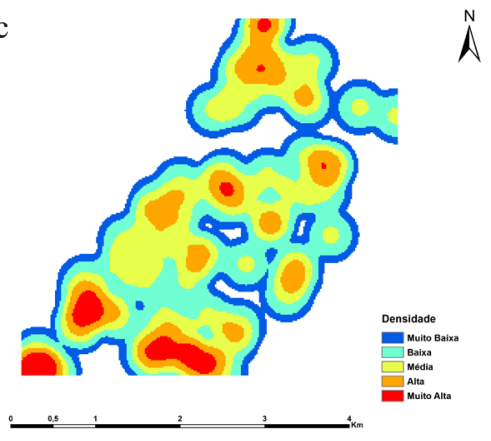

Classe remanescente $(30,0 \leq \mathrm{DAP}<49,9 \mathrm{~cm})$

Classe comercial $(50,0 \leq \mathrm{DAP}<79,9 \mathrm{~cm})$

Classe senescente $(\mathrm{DAP} \geq 80,0 \mathrm{~cm})$
Figura 5. Mapa da distribuição dos indivíduos de Dipteryx odorata em classes de diâmetro, na área de manejo florestal avaliada no município de Santa Carmem, MT.

Figure 5. Distribution map of individuals of Dipteryx odorata in diameter classes, in the forest management area evaluated in the municipality of Santa Carmem, MT.

pesquisa, foram amostradas somente árvores com DAP $\geq 30 \mathrm{~cm}$, as quais são de interesse ao plano de manejo florestal em questão.

Em pesquisa realizada em duas áreas de Floresta de Terra Firme no nordeste do estado do Pará, Rodrigues et al. (1997) observaram em 4 ha de floresta primária, 39 famílias, 99 gêneros e 135 espécies, para uma amostragem acima de $10 \mathrm{~cm}$ de DAP. Já Carim et al. (2013) observaram em 3,4 ha de mesma tipologia florestal, porém no estado do Amapá, também para indivíduos acima de $10 \mathrm{~cm}$ de diâmetro à altura do peito, 
30 famílias, 70 gêneros e 93 espécies. Em ambos os trabalhos, a família Fabaceae foi a que apresentou maior número de indivíduos e de riqueza de espécies, assim como foi observado para a área de estudo desse trabalho.

A família Fabaceae apresenta também maior representatividade em vários outros estudos florísticos realizados na Floresta Amazônica (Ribeiro et al., 1999; Almeida et al., 2012; Condé \& Tonini, 2013; Gualberto et al., 2014; Leão et al., 2018; Lima et al., 2018). Em um levantamento realizado por Ribeiro et al. (2016), para o período de 2004 a 2010, as famílias Fabaceae, Mimosaceae, Moraceae, Meliaceae e Sapotaceae foram as mais representativas em número de espécies madeiráveis comercializadas no estado do Mato Grosso.

Os resultados apresentados para densidade, frequência e dominância para G. glabra e D. odorata (Tabela 1) indicam que, mesmo com valores inferiores ao observado para Qualea spp., essas espécies apresentam importância ecológica na área de estudo, pois apresentaram valores consideráveis para os parâmetros fitossociológicos na análise.

Assim como foi observado neste trabalho, Carim et al. (2013) observaram Dipteryx odorata e Goupia glabra, em Floresta Ombrófila Densa no Amapá, dentre as espécies que apresentaram maiores valores de índice de importância. Silva et al. (2008), também em um ambiente de Terra Firme, em Manaus, AM, registraram para Goupia glabra um valor de importância de $1,09 \%$, inferior ao observado neste trabalho, assim como para Dipteryx odorata, com 1,15\% de índice de valor de importância em Manaus e 5\% na região de Santa Carmem. Em ambos os trabalhos não foi relatada a presença de indivíduos de Qualea spp.

Essas diferenças nos valores de importância de uma mesma espécie, ocorrendo na mesma tipologia florestal, porém, em regiões distantes entre si, indicam a importância de estudos individuais por espécie, ou grupos de espécies com comportamento semelhante de desenvolvimento, pois a ocorrência de microssítios específicos interfere diretamente na dinâmica das espécies.

Há muito tempo têm sido realizados estudos que relacionam a estrutura florística de determinada região com as características ambientais (Rodrigues \& Shepherd, 1992; Ruggiero et al., 2002; Rodrigues et al., 2007). Segundo Rodrigues et al. (2007), características edáficas podem influenciar não só o tipo de formação florestal, mas também a distribuição e a abundância de espécies.
Segundo Amaral et al. (2002), em análise de interpoladores espaciais para a estimativa de densidade na Amazônia, foi observado que o raio de Kernel é adaptativo à estrutura da população local, ou seja, em regiões de baixa densidade não há alteração no tamanho do raio, porém, em regiões de alta densidade, o raio diminui proporcionalmente, podendo cobrir apenas uma parte da célula de saída. Por essa razão, no presente trabalho, optou-se por usar um raio pré-estabelecido de acordo com o cálculo da distância entre árvores proposta por Braz et al. (2015) que, por considerar o número de indivíduos, apresentou uma grande variação $(35 \mathrm{~m} \mathrm{a}$ $370 \mathrm{~m}$ ), sendo o valor menor observado para o censo, ocorrendo um aumento gradual conforme a análise individual das espécies e de suas respectivas densidades.

De maneira geral, o mapa de distribuição de Kernel para os dados do censo (Figura 1a) apresentou alta densidade de indivíduos, com a presença de áreas (manchas vermelhas) com maior concentração de árvores que identificam zonas preferenciais para a condução do manejo florestal na área. Essas são claramente observadas no mapa de Qualea spp. (Figura 1b), pois, mesmo sendo a espécie com maior densidade na área, o cambará apresentou maior dispersão na espacialização da distribuição da densidade, devido ao seu comportamento gregário. Seguindo o padrão observado para o censo, as zonas preferenciais não são as mesmas daquelas de G. glabra e D. odorata.

$\mathrm{O}$ volume de madeira de um povoamento natural varia em função da capacidade produtiva do solo e da distribuição das espécies. Por tais razões, é impossível esperar que uma divisão da área de uma floresta natural em partes iguais corresponda à divisão do volume também em partes iguais (Hosokawa et al., 1998; Braz et al., 2012), apropriada para a exploração de acordo com o ciclo considerado. Por isso, no planejamento das unidades de produção anual (UPAs) (do ponto de vista do planejamento de rede de estradas, pátios e trilhas de arraste), deve-se relacionar as produções volumétricas ou densidade de espécies com subcompartimentos de tamanho variado (unidades de trabalho - UTs). Assim, os sítios de alta densidade devem ter áreas menores e os de baixa densidade, áreas maiores. Isto indica que se deve buscar o planejamento, visando ao fluxo constante, com foco em UPAs otimizadas, apesar da heterogeneidade da floresta (Braz, 2005). Assim, o uso de mapas de densidade de Kernel pode auxiliar na demarcação das UTs, possibilitando o direcionamento da exploração por 
grupo de espécies de interesse comercial, bem como a otimização da alocação das redes de estradas e dos pátios de estocagem.

A riqueza e a diversidade de espécies tropicais podem variar conforme a intensidade amostral (Barros, 1986; Condé \& Tonini, 2013). Fato este também observado por Rolim \& Nascimento (1997), em um estudo conduzido em uma Floresta de Tabuleiro, em Linhares - ES, em área de $40 \mathrm{ha}$, onde foram testadas com os dados do censo, diversas intensidades amostrais. Esses autores também constataram que, apesar de pequenas, diferenças estatisticamente significativas ocorreram na estimativa do índice de Shannon (H'). Em contrapartida, Leão et al. (2018), em estudo realizado no estado do Pará, em área com mais de 4.000 ha de Floresta de Terra Firme, não encontraram diferenças significativas na estimativa do H' entre as intensidades amostrais testadas, tendo seus valores variado de 3,79 a 3,89.

O valor observado para área deste trabalho $(2,45)$ está abaixo dos limites considerados por Knight (1975), para a Floresta Amazônica que varia de 3,83 a 5,85. Quando comparado aos trabalhos realizados em regiões de Terra Firme, o valor é consideravelmente inferior (Almeida et al., 2012), com 4,39; Andrade et al. (2015) encontraram valores de 4,46 e 4,44 para duas áreas; Gualberto et al. (2014) encontraram o valor de 3,36 para o estrato adulto, considerando indivíduos com DAP $\geq 30 \mathrm{~cm}$; Andrade et al. (2017) encontraram um valor médio de 2,96, considerado baixo pelos autores. Apesar do valor de H' observado na área de estudo deste trabalho indicar uma baixa diversidade de espécies, vale destacar a importância da área, pois as espécies com maiores densidades populacionais são aquelas com importância econômica para o setor madeireiro da região.

Ubialli et al. (2009), analisando o índice de agregação de McGuinnes para uma área de floresta natural no estado do Mato Grosso, observaram que, quando houve aumento no tamanho das parcelas (variando de $400 \mathrm{~m}^{2}$ a 1 ha), as espécies passaram de um comportamento de dispersão aleatório para tendência ao agrupamento e espécies que apresentaram tendência ao agrupamento passaram a ser classificadas como gregárias. Possivelmente, a classificação de Qualea spp. como gregária se deu por ser a espécie de maior densidade populacional no local de estudo, ocorrendo em reboleiras espalhadas por toda $\mathrm{a}$ área (Figura 1b).

Segundo Ribeiro et al. (1999), 30\% das espécies são agregadas na região de Carajás e $70 \%$ apresentam tendência ao agrupamento, sendo analisadas 35 parcelas de $20 \mathrm{~m}$ x $200 \mathrm{~m}$. Em Marabá, foram mesuradas 22 parcelas de mesmo tamanho e mais de $80 \%$ das espécies têm comportamento gregário. $\mathrm{O}$ resultado observado em Carajás é semelhante ao observado neste trabalho, onde a maioria das espécies apresentou comportamento com tendência ao agrupamento e somente duas espécies se apresentaram como gregárias.

Admitindo-se que a análise de dispersão realizada no software ArcGIS considera a coordenada geográfica de cada árvore, considera-se que o resultado apresentado é mais confiável do que aquele que foi trabalhado pelo método tradicional (McGuiness, 1934).

De maneira geral, os trabalhos em regiões de Floresta Ombrófila Densa de Terra Firme apresentam a distribuição diamétrica com padrão de "J" invertido (Andrade et al., 2015; Condé \& Tonini, 2013; Leão et al., 2018; Lima et al., 2018). No entanto, a distribuição diamétrica da área total somente apresenta o padrão "J" invertido a partir da classe de $45 \mathrm{~cm}$ (Tabela 2). Para O'Hara (1998), a mortalidade nas classes de diâmetro menores ocorre devido aos altos níveis de competição dentro da classe, além da competição e cobertura por árvores maiores. Segundo Lamprecht (1990), as árvores dominadas somente alcançam o dossel superior da floresta com a abertura de clareiras, seja por ocorrência natural ou por ação antrópica. $\mathrm{O}$ decréscimo de indivíduos na classe anterior a de $45 \mathrm{~cm}$ pode ter ocorrido devido ao superestocamento em área basal no extrato superior (Pascal, 2003) e por dificuldade de estabelecimento dos indivíduos das classes menores (Braz et al., 2014).

Analisando a dinâmica da distribuição diamétrica da família Sapotaceae em Floresta de Terra Firme, após exploração, Reis et al. (2014) observaram que, com exceção da classe inferior e superior, as demais classes diamétricas tiveram um aumento na densidade relativa, 13 anos após a colheita. Segundo os autores, a abertura do dossel da floresta favoreceu o recrutamento das árvores nas diversas classes.

Silva et al. (2008) observaram, em um trecho de Floresta de Terra Firme no Parque Fenológico da Embrapa Amazônia Ocidental, que a maior concentração de indivíduos foi na primeira classe, de $20 \mathrm{~cm}$ a $30 \mathrm{~cm}$ de DAP, sendo que as três primeiras classes somaram $84 \%$ dos indivíduos. Porém, não houve representação de indivíduos nas classes de $85 \mathrm{~cm}$ e $95 \mathrm{~cm}$ de DAP, diferente do que foi observado neste trabalho, onde 
ocorreu maior concentração de indivíduos até a classe de $85 \mathrm{~cm}$, que são as classes passíveis de exploração. Essa é uma vantagem da área de estudo deste trabalho, do ponto de vista de manejo. Por outro lado, a existência de árvores, em classes de maiores diâmetros, depende de sua sobrevivência por classe, até atingir o limite biológico da espécie.

Com os mapas de densidades de Kernel, considerando a distribuição de diâmetro em classes remanescente, comercial e senescente, foi observado que Qualea spp. raramente atinge grandes diâmetros (DAP $>115 \mathrm{~cm}$ ), apresentando baixa sobrevivência na última classe, correspondendo a 2,3\% do total de indivíduos (Figura 3). D. odorata, assim como foi observado para Qualea spp., apresentou na classe superior a $80 \mathrm{~cm}$, relevante queda na quantidade de árvores (Figura 5). No entanto, G. glabra apresentou ocorrência de indivíduos na classe superior a $80 \mathrm{~cm}$ equivalente às demais, indicando baixa mortalidade nessas classes de DAP (Figura 4). Segundo Carvalho (1984), na região Amazônica, espécies de ciclo de vida longo apresentam abundância em todas as classes de diâmetro.

Portanto, pode-se observar pelos mapas que, nas áreas com maior densidade, cabe uma análise diferenciada tanto para o planejamento, priorizando as zonas preferenciais para manejo, considerando as espécies de maior valor comercial no momento e, assim, otimizando a exploração e os custos, como para tratamentos silviculturais diferenciados para áreas de maior ou menor densidade. Diante disso, acredita-se que mapas de densidade possam fornecer informações importantes, tanto para o planejamento do manejo florestal quanto para o entendimento da dinâmica de desenvolvimento da floresta como um todo ou em nível de espécie.

\section{Conclusões}

O uso de métodos tradicionais para a análise florística de florestas tropicais é suficiente para descrever a população. Porém, o uso de análises de sistemas de informações geográficas (SIG) pode ser de grande ajuda no que se refere à visualização desses resultados, permitindo inferir que a aplicação da densidade de Kernel surge como uma ferramenta promissora ao planejamento do manejo florestal, a definição de zonas preferenciais para a exploração sustentável.

\section{Agradecimentos}

O presente trabalho foi realizado com o apoio financeiro da Coordenação de Aperfeiçoamento de Pessoal de Nível Superior - Brasil (Capes) - Código de Financiamento 001. Agradecimentos ao Renato Olivir Basso (Elabore Consultoria) e ao Sindicato das Indústrias Madeireiras do Norte do Mato Grosso (Sindusmad) que apoiaram o desenvolvimento da pesquisa conduzida para o presente trabalho.

\section{Referências}

Almeida, L. S. et al. Fitossociologia e uso múltiplo de espécies arbóreas em floresta manejada, Comunidade Santo Antônio, município de Santarém, Estado do Pará. Acta Amazônica, v. 42, p. 185-194, 2012. http://dx.doi.org/10.1590/S0044-59672012000200002.

Amaral, S. et al. Interpoladores espaciais para geração de superfícies de densidade populacional na Amazônia Brasileira: problemas e perspectivas. In: SIMPÓSIO BRASILEIRO DE GEOINFORMÁTICA, 4., 2002, Caxambu. Anais... Belo Horizonte: Geoinfo, 2002. p. 53-89.

Andrade, D. F. et al. Inventário florestal de grandes áreas na Floresta Nacional do Tapajós, Pará, Amazônia, Brasil. Biota Amazônia, v. 5, n. 1, p. 109-115, 2015. http://www.alice.cnptia.embrapa.br/alice/ handle/doc/1025613.

Andrade, R. T. G. et al. Fitossociologia de uma floresta de terra firme na Amazônia Sul-Ocidental, Rondônia, Brasil. Biota Amazônia, v. 7, n. 2, p. 36-43, 2017. http://dx.doi.org/10.18561/2179-5746/ biotaamazonia.v7n2p36-43.

Andrade Filho, V. S. de et al. Distribuição espacial de queimadas e mortalidade em idosos em região da Amazônia Brasileira, 20012012. Ciência \& Saúde Coletiva, v. 22, n. 1, p. 245-253, 2017. DOI: 10.1590/1413-81232017221.09622015.

Araújo, P. T. M. \& Figueiredo, S. M. de M. Mapeamento e distribuição espacial de focos de calor em anos de secas severas no sul da Amazônia, Brasil. In: SIMPÓSIO BRASILEIRO DE SENSORIAMENTO REMOTO, 18., 2017, Santos. Anais... São Paulo: INPE, 2017. p. 662-668.

Arenas, M. D. et al. Cobertura vegetal de Alta Floresta, Amazônia Meridional Matogrossense. Espacios, v. 36, n. 20, 2015.

Barros, P. L. C. Estudo fisiológico de uma Floresta Tropical Úmida no planalto de Curuá-uma, Amazônia Brasileira. 1986. 158 f. Tese (Doutorado em Engenharia Florestal) - Universidade Federal do Paraná, Curitiba.

Batista, A. P. B. et al. Caracterização estrutural em uma floresta de terra firme no estado do Amapá, Brasil. Pesquisa Florestal Brasileira, v. 35, n. 81, p. 21-33, 2015. https://doi.org/10.4336/2015. pfb.35.81.689.

Brasil. Instrução normativa n ${ }^{\circ} 5$, de 11 de dezembro de 2006. Diário Oficial [da] República Federativa do Brasil, Brasília, DF, seção 1, p. 155, 13 dez. 2006. 
Braz, E. M. Planejamento da exploração em florestas naturais. Colombo: Embrapa Florestas, 2005. (Embrapa Florestas. Documentos, 118). https://www.infoteca.cnptia.embrapa.br/infoteca/ handle/doc/303966.

Braz, E. M. et al. Taxa de corte sustentável para manejo das florestas tropicais. Ciência Florestal, v. 22, n. 1, p. 137-145, 2012. http:// dx.doi.org/10.5902/198050985086.

Braz, E. M. et al. Strategies for achieving sustainable logging rate in the Brazilian Amazon Forest. Open Journal of Forestry, v. 4, n. 2, p. 100-105, 2014. http://dx.doi.org/10.4236/ojf.2014.42015.

Braz, E. M. et al. Criteria to be considered to achieve a suustainable second cycle in Amazon Forest. Pesquisa Florestal Brasileira, v. 35, n. 83, p. 209-225, 2015. https://doi.org/10.4336/2015.pfb.35.83.941.

Broza, K. T. et al. Etapas do planejamento do projeto MODEFLORA em SIG livre. In: SEMINÁRIO DE ATUALIZAÇÃO EM SENSORIAMENTO REMOTO E SISTEMAS DE INFORMAÇÕES GEOGRÁFICAS APLICADOS À ENGENHARIA FLORESTAL, 10., 2012, Curitiba. Anais... Paraná: FUPEF, 2012. p. 651-658.

Caña, B. B. et al. Análise da transformação da floresta Amazônica a partir do uso de geotecnologias - Google Earth Engine - nas aulas de geografia do ensino fundamental. Boletim Gaúcho de Geografia, v. 42, n. 2, p. 553-567, 2015.

Carim, M. J. V. et al. Composição e estrutura de Floresta Ombrófila Densa do extremo norte do Estado do Amapá, Brasil. Biota Amazônia, v. 3, n. 2, p. 1-10. 2013. http://dx.doi.org/10.18561/21795746/biotaamazonia.

Carvalho, J. O. P. de. Manejo de regeneração natural de espécies florestais. Belém: Embrapa-CPATU, 1984. (Embrapa-CPATU. Documentos, 34).

Condé, T. M. \& Tonini, H. Fitossociologia de uma Floresta Ombófila Densa na Amazônia Setentrional, Roraima, Brasil. Acta Amazônica, v. 43 , n. 3, p. 247-260. 2013. http://www.alice.cnptia.embrapa.br/ alice/handle/doc/978261.

Costa, D. L. da. Estrutura e distribuição espacial de Symphonia globulifera L. F. Em floresta de várzea baixa, Afua-PA. Advances in Forestry Science, v. 5, n. 1, p. 275-281, 2018. https://doi. org/10.34062/afs.v5i1.5665.

Costa, F. G. et al. Influência do transporte no uso da terra: o potencial de viabilização da produção de soja na amazônia legal devido ao desenvolvimento da infra-estrutura de transportes. Revista de Economia e Sociologia Rural. v. 39, n. 2, p. 27-50, 2001.

Cunha, J. P. L. da \& Bias, E. S. Uso do mapeamento remoto por radar na identificação de vestígios arqueológicos: estudo de caso do Projeto Radiografia da Amazônia. Revista de Geologia, v. 32, n. 2, p. 199-210, 2019.

Dias Júnior, C. F. et al. Measure: sistema de coleta de informações. Tecno-Lógica, v. 24, n. 1, p. 103-111, 2020. http://dx.doi. org/10.17058/tecnolog.v24i1.13689

Domingues, M. S. \& Bermann, C. O arco de deflorestamento na Amazônia: da pecuária à soja. Ambiente \& Sociedade, v. 15, n. 2, p. 1-22, 2012. http://dx.doi.org/10.1590/S1414-753X2012000200002.

ESRI. Environmental Systems Research Institute. Redlands. ArcGIS Desktop: release 9.3. New York, 2009.
Ferreira, G. P. \& Sano, E. E. Mapa de densidade de Kernel como indicador de desmatamento futuro na Amazônia Legal. In: SIMPÓSIO BRASILEIRO DE SENSORIAMENTO REMOTO, 16., Foz do Iguaçú. Anais... Paraná: INPE, 2013. p. 4404-4410.

Figueiredo, E. O. et al. LIDAR-based estimation of bole biomass for precision management of an Amazonian forest: Comparisons of ground-based and remotely sensed estimates. Remote Sensing of Environment, v. 187, p. 281-293, 2016. https://doi.org/10.1016/j. rse.2016.10.026.

Freitas, P. M. de et al. Software Mata Nativa 2: Sistema de informações aplicado ao manejo de florestas naturais. In: CONGRESSO BRASILEIRO DE AGROINFORMÁTICA, 5., 2005, Londrina. Anais... Paraná: SBI-AGRO, 2005.

Gualberto, M. L. C. et al. Fitossociologia e potencial de espécies arbóreas em ecossistema sucessional na Floresta Nacional do Tapajós, Pará. Agroecossistemas, v. 6, n. 1, p. 45-57, 2014. http://dx.doi. org/10.18542/ragros.v6i1.1593.

Hopkins, M. J. G. Modelling the known and unknown plant biodiversity of the Amazon basin. Journal of Biogeography, v. 34, p.1400-1411, 2007. https://doi.org/10.1111/j.1365-2699.2007.01737.x.

Hosokawa, R. T. et al. Introdução ao manejo e economia florestal. Curitiba: UFPR, 1998. 162 p.

Klauberg, C. et al. Utilizando ferramenta SIG para subsídio ao inventário de um produto florestal não madeireiro (PFNM) do tipo cipó, em área florestal Amazônica. In: SIMPÓSIO BRASILEIRO DE SENSORIAMENTO REMOTO, 17., 2013, Foz do Iguaçú. Anais... Paraná: INPE, 2013. p. 120-128.

Knight, D. H. A. A phytosociological analysis of species-rich tropical forest on Barro Colorado Island, Panama. Ecological Mongraphs, v. 45, p. 259-280, 1975. https://doi.org/10.2307/1942424.

Lamprech, H. Silvicultura nos trópicos: ecossistemas florestais e respectivas espécies arbóreas: possibilidades e métodos de aproveitamento sustentado. Eschbom: Instituto de Silvicultura da Universidade de Göttingen, 1990. 343 p.

Leão, F. M. et al. Sample intensity in ombrophilous open forest at Verde Para Sempre Extractive Reserve, Poto de Moz, PA. Revista Agro@mbiente on-line, v. 12, n. 1, p. 68-79, 2018. http://dx.doi. org/10.18227/1982-8470ragro.v12i1.4472.

Lima, R. B. A. et al. Análises estruturais do componente arbóreo em floresta de Terra Firme, Carauari, Amazonas, Brasil. Biodiversidade, v. 17, n. 1, p. 1-16. 2018.

Martins, F. S. R. V. Análise de ferramentas de SIG para a estimativa de biomassa potencial: um estudo de caso em região de contato floresta/savana, Roraima. In: XV SIMPÓSIO BRASILEIRO DE SENSORIAMENTO REMOTO, 15., 2011, Curitiba. Anais... Paraná: INPE, 2011. p. 4126-4133.

McGuiness, W. G. The relation between frequency index and abundance as applied to plant populations in a semiarid region. Ecology, v. 15, n. 3, p. 263-282, 1934.

Moras Filho, L. O. et al. Classificador de máxima verossimilhança aplicado à identificação de espécies nativas na Floresta Amazônica. In: SIMPÓSIO BRASILEIRO DE SENSORIAMENTO REMOTO, 18., 2017, Santos. Anais... São Paulo: INPE, 2017. p. 1605-1610. http://www.alice.cnptia.embrapa.br/alice/handle/doc/1072220. 
O'hara, K. L. Silviculture for structure diversity: a new look at multiaged systems. Journal of Forestry, v. 96, p. 4-10, 1998. https:// doi.org/10.1093/jof/96.7.4a.

Oliveira, A. N. et al. Composição e diversidade florístico-estrutural de um hectare de floresta densa de terra firme na Amazônia Central, Amazonas, Brasil. Acta Amazonica, v. 38, n. 4, p. 627-641, 2008. http://dx.doi.org/10.1590/S0044-59672008000400005.

Pascal, J. Notions sur les structures et dynamique des forêts tropicales humides. Revue Forestière Française, v. 55, p. 118-130. 2003. https://doi.org/10.4267/2042/5765.

Passos, C. A. M. \& Mason, R. J. Potencial madeireiro do estado do Mato Grosso. Várzea Grande: CIPEM, 2005. 69 p.

Pellico Netto, S. \& Brena, D. A. Inventário florestal. Curitiba, 1997.

Reis, L. P. et al. Dinâmica da distribuição diamétrica de algumas espécies de Sapotaceae após exploração florestal na Amazônia Oriental. Revista Ciências Agrárias, v. 57, n. 3, p. 234-243, 2014.

Ribeiro, E. S. et al. Espécies florestais comercializadas pelo estado de Mato Grosso. Biodiversidade, v. 15, n. 2, p. 2-20, 2016.

Ribeiro, R. J. et al. Estudo fitossociológico nas regiões de Carajás e Marabá - Pará, Brasil. Acta Amazonica, v. 29, n. 2, p. 207-207, 1999. https://doi.org/10.1590/1809-43921999292222.

Rodrigues R. R. \& Shepherd, G. J. Análise da variação estrutural e fisionômica da vegetação e características edáficas, num gradiente altitudinal na Serra do Japi. In: Morellato, L. P. C. (org.). História natural da Serra do Japi: ecologia e preservação de uma área florestal no sudeste do Brasil. Campinas: Ed Unicamp, 1992. p. 64-96.

Rodrigues, I. A. et al. Levantamento fitossociológico em áreas sob influência da rodovia PA-150 nos municípios de Aracá e Tailândia, PA. Belém: Embrapa Amazônia Oriental, 1997. (Embrapa Amazônia Oriental. Boletim de Pesquisa, 179).

Rodrigues, L.A. et al. Efeitos de solos e topografia sobre a distribuição de espécies arbóreas em um fragmento de floresta estacional semidecidual, em Luminárias, MG. Revista Árvore, v. 31, n. 1, p. 25-35, 2007. https://doi.org/10.1590/S0100-67622007000100004.

Rolim, S. G. \& Nascimento, H. E. M. Análise da riqueza, diversidade e relação espécie-abundância de uma comunidade arbórea tropical em diferentes intensidades amostrais. Scientia Forestalis, n. 52, p. 7-16, dez. 1997. https://www.researchgate.net/publication/237244297.

Ruggiero, P. G. C. et al. Soil-vegetation relationships in Cerrado (Brazilian savanna) and Semideciduous Forest, Southeastern Brazil. Plant Ecology, v. 160, p.1-16, 2002. https://doi. org/10.1023/A:1015819219386.

Schneider, P. R. \& Schneider, P. O. Manejo Florestal. Santa Maria: Universidade Federal de Santa Maria. Centro de Ciências Rurais. Departamento de Ciências Florestais, 2008.
Silva, J. N. M. \& Lopes, J. do C. A. Inventário florestal contínuo em florestas tropicais: a metodologia utilizada pela Embrapa CPATU na Amazônia Brasileira. Belém: Embrapa-CPATU, 1984. (EmbrapaCPATU. Documentos, 36).

Silva, K. E. da et al. Composição florística e fitossociológica de espécies arbóreas do Parque Fenológico da Embrapa Amazônia Ocidental. Acta Amazonica, v. 38, p. 213-222, 2008.

Silva, L. S. \& França, C. A. S. M. SIG como ferramenta de mapeamento das formas de uso e ocupação do solo na APA Igarapé São Francisco, Rio Branco, Acre. In: SIMPÓSIO BRASILEIRO DE SENSORIAMENTO REMOTO, 16., 2013, Foz do Iguaçú. Anais... Paraná: INPE, 2013. p.

Silva, K. E. et al. Dinâmica florestal, estoque de carbono e fitossociologia de uma floresta densa de terra-firme na Amazônia Central. Scientia Forestalis, v. 43, n. 105, p. 193-201, 2015.

Silva, E. F. et al. Allocation of Storage Yards in Management Plans in the Amazon by Means of Mathematical Programming. Forests, v. 9, n. 3, 2018. https://doi.org/10.3390/f9030127.

Silva, E. F. da et al. Optimized forest planning: allocation of log storage yards in the Amazonian sustainable forest management area. Forest Ecology and Management, v. 472, p. 1-9, 2020. https://doi. org/10.1016/j.foreco.2020.118231.

Silverman, B. W. Density estimation for statistics and data analysis. Chapman \& Hall, London. 1986. 176 p.

Souza, N. P. de et al. Aplicação do estimador de densidade Kernel em unidades de conservação na Bacia do Rio São Francisco para análise de focos de desmatamento e focos de calor. In: SIMPÓSIO BRASILEIRO DE SENSORIAMENTO REMOTO, 16., 2013, Foz do Iguaçú. Anais... Paraná: INPE, 2013. p. 4958-4965.

Tavares, P. A. Clima, antropização e análise de focos de calor em unidades de conservação de proteção integral na Amazônia Brasileira. In: SIMPÓSIO BRASILEIRO DE SENSORIAMENTO REMOTO, 19., 2019, Santos. Anais... São Paulo: INPE, 2019. 5 p.

Ubialli, J. A. et al. Comparação de métodos e processos de amostragem para estudos fitossociológicos em uma floresta ecotonal na região norte matogrossense. Floresta, v. 39, n. 3, p. 511-523, 2009. http://dx.doi.org/10.5380/rf.v39i3.15351.

Umetsu, R. K. et al. Análise morfométrica e socioambiental de uma bacia hidrográfica Amazônica, Carlinda, MT. Revista Árvore, v. 36, n. 1, p. 83-92, 2012. https://doi.org/10.1590/S010067622012000100010 .

Vale, J. R. B. \& Bordalo, C. A. L. Caracterização morfométrica e do uso e cobertura da terra da bacia hidrográfica do Rio Apeú, Amazônia Oriental. Formação (Online), v. 27, n. 51, p. 313-335, 2020. https:// doi.org/10.33081/formacao.v27i51.6026 